\title{
The psychosocial impact of assistive device scale: Italian validation in a cohort of nonambulant people with neuromotor disorders
}

M Tofani, C Candeloro, M Sabbadini, L Lucibello, M Figura, G Fabbrini, G Galeoto \& E Castelli

To cite this article: M Tofani, C Candeloro, M Sabbadini, L Lucibello, M Figura, G Fabbrini, G Galeoto \& E Castelli (2018): The psychosocial impact of assistive device scale: Italian validation in a cohort of nonambulant people with neuromotor disorders, Assistive Technology, DOI: 10.1080/10400435.2018.1469553

To link to this article: https://doi.org/10.1080/10400435.2018.1469553

Accepted author version posted online: 25

Apr 2018.

Submit your article to this journal ¿

Q View related articles ¿

View Crossmark data ¿ 


\section{The Psychosocial Impact of Assistive Device Scale: Italian validation in a cohort of nonambulant people with neuromotor disorders}

Tofani $M^{1}$ Candeloro $C^{1}$ Sabbadini $M^{1}$ Lucibello ${ }^{2}$ Figura $M^{3}$, Fabbrini $G^{4}$, Galeoto $G^{5}$, Castelli $\mathbf{E}^{1}$

1 Department of Neuroscience and Neurorehabilitation, Bambino Gesù Children's Hospital Rome - Italy

2 ITOP Officine Ortopediche, Palestrina (Rome) - Italy

3 Sapienza Università of Rome, Rome-Italy

4 Department of Neurology and Psychiatry, "Policlinico Umberto I" University Hospital Sapienza- University of Rome, IRCSS Neuromed Institute Pozzilli (IS) - Italy

5 Department of Public Health and Infectious Diseases, Sapienza University of Rome, Rome Italy

Author Note

The authors are grateful to Rosa Maria Conte for her kind contribution. Furthermore, the authors wish to thank the Rehabilitation and Outcome Measures Assessment (ROMA): a no profit organization which spreads evidence best practice in the field of rehabilitation.

\section{Abstract}

The importance of adaptive seating system on body structure and function is widely accepted, but its impact on psychosocial aspects needs more consideration by health professionals. This article describes the Italian validation of the Psychosocial Impact of Assistive Device Scale (ITPIADS) for non-ambulant people with neuromotor disorders. 
Once agreement has been given by the original authors, the scale was translated and adapted to the Italian culture. The IT-PIADS was administered to different wheelchairs users with heterogeneous diagnosis. The internal consistency and test-retest reliability were examined. Its concurrent validity was evaluated with the Italian version of the WheelCon-M-SF.

The IT-PIADS was administered to 87 subjects. Cronbach's $\alpha$ was $0.92(\mathrm{p}<0.05)$, and the testretest reliability (ICC) for competence, adaptability and self-esteem subscales were 0.96, 0.90, 0.93 respectively. The Pearson correlation coefficient of the IT-PIADS with the WheelConM-I-SF scores showed significant data for competence and adaptability subscales.

Psychosocial perception on assistive devices can be reliably measure. The IT-PIADS showed good psychometric properties and it is possible to confirm its validity for clinical and research purposes. Nevertheless, before using this measure with greater confidence, further psychometric properties tests of the IT-PIADS are recommended.

Keywords: psychosocial, assistive technology, outcome measure (health assessment), validation, Italian, PIADS

Assistive devices and technology (ADT) is any form of external tool specially designed and produced or generally available, whose primary purpose is to maintain or improve an individual's functioning and independence, to facilitate participation, and to enhance overall well-being (WHO, 2014). Even though the effectiveness of ADT is widely accepted, around the world a high rate of non-use is registered (Cruz, Emmel, Manzini, \& Braga Mendes, 2016; Wessels, Dijcks, Soede, Gelderblom, \& De Witte 2003). Instruments and tools help to analyse 
factors and to identify potential policies and actions that can improve the accessibility and optimal use of assistive products (WHO, 2017).

Although a number of tools are available, Italian language assessment tools for measuring impact of assistive technology are needed. In Italy $17.9 \%$ the people who need ADT declared they do not use them (Federici, Meloni, \& Borsci, 2016); abandonment may be due to assignment of inappropriate devices or failure to meet user needs and expectations (Federici, \& Borsci, 2016, Federici, \& Borsci, 2011). Therefore, a holistic approach is necessarily required in assessing the impact of ADT and psychosocial aspects need more consideration by health professionals. Investigating the psychosocial perception of the ADT users could clarify the reasons why different assistive technologies are abandoned and reduce the risk of inappropriate prescriptions in order to optimize resources of the Italian National Health System.

Therefore, intercepting psychosocial aspects seems crucial to affect the quality of life (QoL) of ADT users, but worldwide these perspectives can differ from each other; consequently it is important to consider also the social and cultural factors of the context where the assessment tool is going to be performed.

The importance of adapting instruments to current research settings is widely documented in international literature (Maher, Latimer, \& Costa 2007; Gjersing, Caplehorn, \& Clausen 2010) and there is agreement that it is inappropriate to simply translate and use a questionnaire in another linguistic context (Wang, Lee, \& Fetzer,2006). The reasons may be different: 1) this allows to fully understand cultural peculiarities of a specific community; 2) the use of validated and cross-cultural adapted instruments increases the certainty with which the instruments 
accurately reflect what they are supposed to measure (Laake, Benestad, \& Olsen, 2007); 3) it enables comparisons of results across different studies both nationally and internationally (Laake et al, 2007).

The Psychosocial Impact of Assistive Device Scale (PIADS) is a 26-item, self-report questionnaire to assess the effects of an assistive device on functional independence, well-being, and quality of life (Day, 1996). The PIADS is capable of predicting device retention and abandonment (Day, Jutai, Woolrich, \& Strong, 2001) in virtue of its ability to intercept also the psychosocial aspects that may influence people's quality of life when using an ADT. A factor analysis divided the PIADS in subscale: 1) Competence (12 items), measures feelings of competence and efficacy; 2) Adaptability (6 items), indicates a willingness to try out new things and to take risks; 3) Self-esteem (8 items), indicates feelings of emotional health and happiness; (Jutai \& Day, 2002). The PIADS is validated in different countries such as Canada (Demers, Monette, Descent, Jutai \& Wolfson, 2002), Korea (Chae \& Jo, 2014), China (Hsieh \& Lenker, 2006); it has also followed a cross-cultural adaptation in Puerto Rican ADT users (Orellano \& Jutai, 2013 Orellano-Colón, Jutai, Santiago, Torres, Benítez, \& Torres, 2016).

The PIADS is a reliable, valid, and responsive measure, with good clinical utility across several populations of device users (Jutai et al, 2002). The assessment tool has a surprisingly good agreement between user self-report and caregiver report of device impact on the user (Jutai, Woolrich, Campbell, Gryfe, \& Day, 2000); so it is possible to use the PIADS in developmental disabilities or in other conditions which require a high care-giver support. Considering the usefulness of the PIADS and its importance in clinical practice, the 
purpose of the present study is to cross-cultural adapt and validate the Italian version of the PIADS in a population of ADT users.

\section{Method}

To investigate the psychometric properties in the Italian version of the PIADS (IT-PIADS), a cross-sectional study was designed. Once agreement has been given by the original authors, the research protocol was drafted as recommended by international guidelines (Wild et al, 2005). The institutional review board approved the study.

\section{Participants}

The pre-established sample size was determined by analysing others validation studies (sample size range 45 - 83 individuals). Therefore a non-probability convenience sample of minimum 70 people were set up. Considering the objective of the present research, both non-ambulant adults and children with neuromotor disorders were included in the cohort. Most common neurological disabilities requiring mobility with ADT were analysed, so patients with stroke, spinal cord injury, Parkinson diseases, cerebral palsy and traumatic brain injury were included. All the participants had to respect the following criteria: have aforementioned neuromotor disorders, age range $6-65$ years, using the wheelchair in their everyday life activities. Being able to understand instructions in Italian was clinically determined. Moreover, patients, who needed supervision or were unable to follow the instructions recommended by the original study, could be helped or 
substituted by their caregivers or guardians in compiling the IT-PIADS. Instead patients with other medical complication (e.g. orthopaedic surgery) were excluded.

\section{Data collection measure}

A questionnaire was designed to describe socio-demographic information of the study sample; the data collected regarded age, sex, education level, diagnosis.

To measure concurrent validity of the IT-PIADS, the Italian version of the Wheelchair Use Confidence Scale short form (WheelCon-M-I short form) (Berardi A, et al 2017) was used. The WheelCon-M short form, a 21-item self-report questionnaire, measures the patient's confidence in managing the wheelchair in the physical and social environment. Each item is scored using a 10-point Likert scale ranging from"0"(not confident) to"10"(completely confident) (Rushton, Miller, Lee Kirby, Eng, \& Yip, 2011). The WheelCon-M short form resulted to be reliable and a valid tool to assess self-confidence in different wheelchair users (Sakakibara, Miller, \& Rushton, 2015; Sakakibara, Miller, Souza, Nikolova, \& Best, 2013)

\section{Procedures and data analysis}

First the researchers (an occupational therapist, a physical therapist, a neurologist and a physician specialized in rehabilitative medicine) assessed the participants according to the mentioned inclusion criteria. Then, in a synchronized individual face-to-face meeting, the same participants were given a detailed explanation of the study and the consent form to be signed (Galeoto, De Santis, Marcolini, Cinelli \& Cecchi, 2016; Galeoto, Mollica, Astorino, \& Cecchi, 
2015). Finally, all participants were asked to complete a socio-demographic questionnaire followed by the administration of the WheelCon-M-I short form (Berardi et al, 2017) (only for adults because no validation study involved developmental disabilities) and the IT-PIADS, as recommended by the PIADS manual (Day, \& Jutai, 2003).

Translation and Cultural Adaptation. The original version of the PIADS was forwardtranslated into Italian by two health professionals (an occupational therapist and a physician specialised in rehabilitative medicine). Then bilingual experts together (a neurologist, a biomedical engineer, a physiotherapist and an occupational therapist) identified and resolved an inadequate or inappropriate translation by comparing the translated version of the PIADS with the original; the result was a preliminary draft of the scale in the target language. Afterwards, an independent translator whose mother tongue is English translated-back the document. The backtranslated version was compared with the original. Finally, in order to optimize the cultural adaptation, the expert panel synthetized the results into a pre-final Italian version of the PIADS (IT-PIADS).

Pilot testing phase. The pre-final version of the IT-PIADS was preliminary applied to 20 adult patients to evaluate cross-cultural validity. To be sure that no clinical changes had occurred, a repetitive administration of the scale was performed in a ranging period of six to eight days. To achieve cross cultural equivalence between the original and the Italian version of the PIADS, semantic domain was analyzed according to participants' recommendations.

Validity and reliability tests phase. To assess intra-rater reliability the same patients were evaluated twice throughout 7-14 days. As recommended by the original, French and 
Korean versions the reliability was investigated to adult patients. The intraclass correlation coefficient (ICC) was used to assess test-retest reliability; the scale was considered as stable at the test-retest for ICC $>0.70$. (Nunually, 1994)

The internal consistency was used to assess the homogeneity of the scale and the interrelatedness of the items. The research group, decided to investigate the internal consistency on the whole study sample. The $\alpha$ coefficient should be at least 0.70 . In fact, according to international literature (DeVellis, 1991), values can be interpreted as follows: 0.70-0.79, respectable, $0.80-0.90$, very good; a values greater than 0.90 indicate excellent internal consistency.

The concurrent validity (Pearson's Correlation) was evaluated comparing the IT-PIADS score with the values of the Italian version of the Wheelchair Use Confidence Scale short form (WheelCon-M-I short form) (Berardi et al, 2017). This assessment tool does not tap the selfesteem at all, so the concurrent validity of the self-esteem part of the scale has not been investigated.

Considering that no studies explore wheelchair confidence in developmental disabilities, the research group decided to investigate concurrent validity only on adults.

All statistical analysis were carried out by using Statistical Package for Social Sciences. 


\section{Results}

Between March and September 2017, the participants were recruited from Bambino Gesù Children's Hospital and Policlinico Umberto I University Hospital in Rome. The IT-PIADS was administered to 87 people; the WheelCon-M-I short form was used to assess 28 people of the sample.

\section{Translation and cultural adaptation phase}

After the forward and backward translation and the consensus of the expert panel, the translated version of the IT-PIADS was formed. From the analysis of the report it was possible drawing-up the pre-final version of the IT-PIADS.

\section{Pilot testing phase}

The prefinal version of the IT-PIADS was administered to 20 adult individuals in March 2017. On the basis of the analysis obtained from the preliminary application, some items were modified to improve comprehensibility and applicability. For example, the word "independence" in Italian is commonly translated as "indipendenza". In Italian, this word also means being economically independent. Participants suggest to translate it with the synonymous "autonomia" which best represents the concept of "Not dependent on, or not always needing help from someone or something" as reported in the manual. Moreover, the semantical equivalence was obtained by modifying grammatical structure of some items; for example "embarrassed" was 
first translated with "imbarazzo". Participants suggest to use the synonymous "disagio" (because more courteous) and to add the substantive "sensazione". Therefore, for a better comprehension, item 21 was changed to "sensazione di disagio" (feeling embarrassed). From the participants" observation it was possible to improve the comprehension of the instrument. This led to the latest Italian version of IT-PIADS applied to the entire study population.

\section{Participants}

87 subjects $(41 \mathrm{~F}-46 \mathrm{M})$ were included in the cross-sectional study. The characteristics are summarized in Table 1.

[INSERT Table 1. Characteristic of the sample]

\section{Validity and reliability tests phase}

The Cronbach's $\alpha$ for the IT-PIADS was $0.92(\mathrm{p}<0.01)$. The internal consistency showed significant results: item-item correlation was significant with a $p$ value $<0.05$, as well as the item-total correlation, as reported in Table 2.

[INSERT Table 2. Item total statistics]

The test-retest reliability was evaluated on 28 subjects. The IT-PIADS showed an ICC of 0.96, 0.90 and 0.93 in Competence, Adaptability and Self-esteem subscales respectively. ICC values are reported in Table 3 . 
[INSERT Table 3. Test-retest reliability]

The Pearson correlation coefficient of the IT-PIADS and the WheelCon-M-I short form showed significant values for Competence $(\mathrm{p}<0.05)$ and Adaptability Subscales $(\mathrm{p}<0.01)$. The results are summarized in Table 4 .

[INSERT Table 4. Pearson Correlation Coefficient]

\section{Discussions}

The purpose of the present study was to develop the Italian version of the PIADS and to evaluate its reliability and validity. The article also reported the cross-cultural adaptation of the IT-PIADS, that was performed as the original version of the assessment tool.

The original version of the PIADS was translated and culturally adapted into Italian according to international guidelines (Wild et al, 2005). Equivalence between the IT-PIADS with the original version was investigated on semantical domain. Participants' observation allowed to gain cross-cultural validity and proved to be strictly related to the meaning of the original items. This resulted in the final version of the IT-PIADS (see Appendix 1).

Participants of the study were non-ambulant people with neuromotor disorders using an assistive mobility devices (wheelchair). The sample showed heterogeneous characteristics in terms of age and diagnosis, nevertheless the finding demonstrated good psychometric properties of the IT-PIADS. 
The test-retest correlation showed significant value for competence (0.96), adaptability (0.90) and self-esteem (0.93) subscales, in line with the original (Day, 1996; Jutai et al, 2002), and also with the Korean (Chae et al, 2014), Chinese (Hsieh et al, 2006) and Canadian (Demers et al 2002) version. This value confirmed a high stability of the scale with a range of good to excellent reliability.

The overall Cronbach's $\alpha$ value of 0.92 is an excellent index of internal consistency and it is comparable to the Chinese (0.95), Korean (0.94), French-Canadian (0.94) and the original (0.95) versions. This finding demonstrates an excellent correlation of the items and high homogeneity of the scale.

The Pearson's Correlation Coefficient of the IT-PIADS demonstrated good concurrent validity. In particular physical subscale of the WheelCon-M-I short form (Berardi et al, 2017) had good correlation with competence and adaptability subscales of the IT-PIADS with a $\mathrm{p}<0.005$ and $\mathrm{p}<0.001$, respectively. The environment subscale had good correlation with the adaptability subscale of the IT-PIADS for a $\mathrm{p}<0.05$. Both Competence and Adaptability subscales of IT-PIADS showed a correlation with the overall value of the WheelCon-M-I short form with a $\mathrm{p}<0.005$ and $\mathrm{p}<0.001$, respectively.

\section{Conclusion}

Based on our finding, it is possible to state the IT-PIADS showed good psychometric properties and its usefulness in clinical and research practice. Nevertheless, the present study has some limitations: the heterogeneity and the relative small sample size did not permit to stratify 
according to specific diagnoses and to evaluate the differences between the participants. Although the objective of the study was to validate the Italian version of the PIADS in a population of wheelchair users, it would be useful to understand which item is more relevant based on needs and proper characteristics of the patients. In fact, it is possible that psycho-social aspect can differ according to age and lifestyles of the ADT users and consequentially there is the possibility that some items in the scale might work differently across subgroups. Therefore, before using this measure with greater confidence, further psychometric properties tests of the IT-PIADS are recommended.

Disclosure of statement. The authors declare that they have no conflict of interest.

Statement of Human and Animal Rights: All procedures followed were in accordance with the ethical standards of the responsible committee on human experimentation (institutional and national) and with the Helsinki Declaration of 1975, as revised in 2008.

Statement of informed Consent. Informed consent was obtained by all the participants included in the study.

Funding. All authors have no commercial associations or disclosures that may pose or create a conflict of interest with the information presented within this manuscript. 


\section{Citations and References}

Berardi, A., De Santis, R., Tofani, M., Márquez, M. A., Santilli, V., Rushton, P. W., Mollica R., \& Galeoto, G. (2017). The Wheelchair Use Confidence Scale: Italian translation, adaptation, and validation of the short form. Disability and Rehabilitation: Assistive Technology, 1-6.

DOI: $10.1080 / 17483107.2017 .1357053$

Chae, S. Y., \& Jo, S. J. (2014). Development and Validation of Korean Version of Psychosocial Impact of Assistive Devices Scale. Assistive Technology, 26(1), 45-50. DOI: $10.1080 / 10400435.2013 .796502$

Cruz, D., Emmel, M. L. G., Manzini, M. G., \& Braga Mendes, P. V. (2016). Assistive technology accessibility and abandonment: challenges for occupational therapists. The Open Journal of Occupational Therapy, 4(1), 10. DOI: 10.15453/2168-6408.1166

Day H., Jutai J., Woolrich W., \& Strong WH. (2001). The stability of impact of assistive devices. Disability and rehabilitation, 23(9), 400-404. DOI : 10.1080/09638280010008906

Day, H. (1996). Measuring the psychosocial impact of assistive devices: The PIADS. Canadian Journal of Rehabilitation, 9(2), 159-168.

Day, H., Jutai, J., \& Campbell, K. A. (2002). Development of a scale to measure the psychosocial impact of assistive devices: lessons learned and the road ahead. Disability and rehabilitation, 24(1-3), 31-37. https://doi.org/10.1080/09638280110066343 
Day, H., \& Jutai, J. (2003). Psychosocial Impact of Assistive Devices Scale (PIADS) Manual. Ontario: University of Western Ontario.

DeVellis RF. Scale Development Theory andApplications. Newbury Park: Sage, 1991.

Demers, L., Monette, M., Descent, M., Jutai, J., \& Wolfson, C. (2002). The Psychosocial Impact of Assistive Devices Scale (PIADS): translation and preliminary psychometric evaluation of a Canadian-French version. Quality of life research, 11(6), 583-592.

http://dx.doi.org/10.1023/A:1016397412708

Federici, S., Meloni, F., \& Borsci, S. (2016). The abandonment of assistive technology in Italy: a survey of National Health Service users. European journal of physical and rehabilitation medicine, 52(4), 516-526.

Federici, S., \& Borsci, S. (2016). Providing assistive technology in Italy: the perceived delivery process quality as affecting abandonment. Disability and Rehabilitation: Assistive Technology, 11(1), 22-31. https://doi.org/10.3109/17483107.2014.930191

Federici, S., \& Borsci, S. (2011). The use and non-use of assistive technology in Italy: Preliminary data. In 11th AAATE Conference: Everyday technology for independence and care. doi:10.3233/978$1-60750-814-4-979$

Galeoto, G., De Santis, R., Marcolini, A., Cinelli, A., \& Cecchi, R. (2016). Il consenso informato in Terapia Occupazionale: proposta di una modulistica. Giornale italiano di medicina del lavoro ed ergonomia, 38(2), 107-115. 
Galeoto, G., Mollica, R., Astorino, O., \& Cecchi, R. (2015). Informed consent in physiotherapy: proposal of a form. Giornale italiano di Medicina del Lavoro ed Ergonomia, 37(4), 245-254.

Gjersing, L., Caplehorn, J. R., \& Clausen, T. (2010). Cross-cultural adaptation of research instruments: language, setting, time and statistical considerations. BMC medical research methodology, 10(1), 13. https://doi.org/10.1186/1471-2288-10-13

Hsieh, Y. J., \& Lenker, J. A. (2006). The psychosocial impact of assistive devices scale (PIADS): Translation and psychometric evaluation of a Chinese (Taiwanese) version. Disability and Rehabilitation: Assistive Technology, 1(1-2), 49-57.

https://doi.org/10.1080/09638280500167217

Jutai, J., \& Day, H. (2002). Psychosocial impact of assistive devices scale (PIADS). Technology and Disability, 14(3), 107-111.

Jutai, J., Woolrich, W., Campbell, K., Gryfe, P., \& Day, H. (2000). User-caregiver agreement on perceived psychosocial impact of assistive devices. In Proceedings of RESNA (pp. 328-330).

Laake, P., Benestad, H. B., \& Olsen, B. R. (Eds.). (2007). Research methodology in the medical and biological sciences. Academic Press.

Maher, C. G., Latimer, J., \& Costa, L. O. (2007). The relevance of cross-cultural adaptation and clinimetrics for physical therapy instruments. Brazilian journal of physical therapy, 11(4), 245252. http://dx.doi.org/10.1590/S1413-35552007000400002

Nunnally, J. C. BI. Psychometric theory New York: McGrawHill Inc; 1994. 
Orellano, E. M., \& Jutai, J. W. (2013). Cross-cultural adaptation of the Psychosocial Impact of Assistive Device Scale (PIADS) for Puerto Rican assistive technology users. Assistive Technology, 25(4), 194-203. https://doi.org/10.1080/10400435.2012.761292

Orellano-Colón, E. M., Jutai, J., Santiago, A., Torres, V., Benítez, K., \& Torres, M. (2016). Assistive Technology Needs and Measurement of the Psychosocial Impact of Assistive Technologies for Independent Living of Older Hispanics: Lessons Learned. Technologies, 4(3), 21. doi:10.3390/technologies4030021

Rushton, P. W., Miller, W. C., Lee Kirby, R., Eng, J. J., \& Yip, J. (2011). Development and content validation of the Wheelchair Use Confidence Scale: a mixed-methods study. Disability and $\begin{array}{lll}\text { Rehabilitation: } & \text { Assistive } & \text { 5echnology, }\end{array}$ https://doi.org/10.3109/17483107.2010.512970

Sakakibara, B. M., Miller, W. C., \& Rushton, P. W. (2015). Rasch analyses of the wheelchair use confidence scale. Archives of physical medicine and rehabilitation, 96(6), 1036-1044. https://doi.org/10.1016/j.apmr.2014.11.005

Sakakibara, B. M., Miller, W. C., Souza, M., Nikolova, V., \& Best, K. L. (2013). Wheelchair skills training to improve confidence with using a manual wheelchair among older adults: a pilot study. Archives of physical medicine and rehabilitation, 94(6), 1031-1037.

Wang, W. L., Lee, H. L., \& Fetzer, S. J. (2006). Challenges and strategies of instrument translation. Western Journal of Nursing Research, 28(3), 310-321. https://doi.org/10.1177/0193945905284712 
Wessels, R., Dijcks, B., Soede, M., Gelderblom, G. J., \& De Witte, L. (2003). Non-use of provided assistive technology devices, a literature overview. Technology and disability, 15(4), 231-238.

Wild, D., Grove, A., Martin, M., Eremenco, S., McElroy, S., Verjee-Lorenz, A., \& Erikson, P.(2005). Principles of good practice for the translation and cultural adaptation process for patient-reported outcomes (PRO) measures: report of the ISPOR task force for translation and cultural adaptation. Value in health, 8(2), 94-104. DOI: 10.1111/j.1524-4733.2005.04054.x

World Health Organization (2014). Concept Note: Opening the GATE for Assistive Health Technology: Shifting the paradigm. (Available http://www.who.int/phi/implementation/assistive_technology/concept_note.pdf, accessed 2 November 2017).

World Health Organization. (2017). Global priority research agenda for improving access to high$\begin{array}{llll}\text { quality affordable } & \text { assistive } & \text { (Available }\end{array}$ http://apps.who.int/iris/bitstream/10665/254660/1/WHO-EMP-IAU-2017.02-eng.pdf, accessed 2 November 2017) 


\section{IT-PIADS: PSYCHOSOCIAL IMPACT OF ASSISTIVE DEVICES SCALE}

Cognome:

Nome:

Genere: $\square \mathrm{M} \quad \square \mathrm{F} \diamond \wedge$ Diagnosi:

Data di Nascita:

Ausilio:

Il modulo seguente è stato compilato a:

$\square$ Domicilio $\square$ Ospedale / Clinica $\square$ Altro

Il modulo seguente è stato compilato da: $\square$ il paziente, senza alcun aiuto con supporto

$\square$ il caregiver in sostituzione del paziente $\square$ $\square$ Il paziente, caregiver Altro

Ogni voce che segue, descrive come l'utilizzo di un ausilio può influenzare la vita di una persona. Alcune di queste affermazioni potranno sembrare inusuali ma è imnortante che Lei risponda ad ognuna delle 26 domande. Per og \begin{tabular}{|ccc}
\multicolumn{3}{r}{ Ha diminuito } \\
molto & abbastanza & poco \\
-3 & -2 & -1
\end{tabular} \mid Non ha
influito Ha aumentato poco abbastanza molto $+1+2 \quad+3$ casella più appropriata indicando quanto l'utilizzo dell'ausilio ha influenzato la Sua quotidianità. 
1) Competenza

$\begin{array}{llllll}\square & \square & \square & \square & \square & \square\end{array}$

$\square$

2) Felicità

$\square \quad \square \quad \square \quad \square \quad \square \quad \square>\quad \square$

\begin{tabular}{|lllllll}
\hline 3) Autonomia & $\square$ & $\square$ & $\square$ & $\square$ & $\square$ & $\square$
\end{tabular}$\quad \square \quad$\begin{tabular}{lll}
\hline \\
\hline
\end{tabular}

4) Adeguatezza

$\square \quad \square \quad \square \quad \square \quad \square$

\begin{tabular}{|r|r|}
\hline \\
\hline
\end{tabular}

5) Confusione

$\square \bigcirc \square \cup \square \quad \square \quad \square \quad \square$

$\square$

6) Efficienza

$\square \quad \square \quad \square \quad \square \quad \square \quad \square$ $\square$

7) Autostima

$\square \quad \square \quad \square \quad \square \quad \square \quad \square$

$\square$

8) Produttività

$\square \quad \square \quad \square \quad \square \quad \square \quad \square$

\begin{tabular}{|c|c|c|c|c|c|c|c|}
\hline 9) Sicurezza & & $\square$ & $\square$ & $\square$ & $\square$ & $\square$ & $\square$ \\
\hline$\square$ & & & & & & & \\
\hline 10) Insoddisfazione & $\square$ & $\square$ & $\square$ & $\square$ & $\square$ & $\square$ & $\square$ \\
\hline
\end{tabular}


11) Sensazione di Utilità

$\begin{array}{llllll}\square & \square & \square & \square & \square\end{array}$

12) Fiducia in sé stesso

$\square \quad \square \quad \square \quad \square \quad \square \quad \square$

प

13) Abilità $\square \quad \square \quad \square \quad \square \quad \square \quad \square \quad \square$

14) Destrezza $\square \quad \square \quad \square$

$\square \quad \square$

15) Benessere

$\square \sim \square \cup \square \quad \square \quad \square \quad \square$

$\square$

16) Capacità

$\square \quad \square \quad \square \quad \square \quad \square \quad \square$

$\square$

17) Qualità di Vita

$\square \quad \square \quad \square \quad \square \quad \square \quad \square$

$\square$

18) Prestazione

$\square \quad \square \quad \square \quad \square \quad \square \quad \square \quad \square \quad \square$

$(2)$

19) Sensazione di potere

$\square \quad \square \quad \square$
$\square \quad \square \quad \square \quad \square$

$\square$

20) Sensazione di controllo

$\square \quad \square \quad \square \quad \square \quad \square \quad \square$

$\square$ 
21) Sensazione di disagio

$\square \quad \square \quad \square \quad \square \quad \square \quad \square$

22) Inclinazione al cambiamento

$\square \quad \square \quad \square \quad \square>\quad \square$

$\square \quad \square$

23) Partecipazione

$\square \quad \square \quad \square \quad \square \quad \square$

\begin{tabular}{|r|r|}
\hline \\
\hline
\end{tabular}

24) Entusiasmo nel provare nuove cose $\square>\square-\square$

$\square \quad \square \quad \square$

\begin{tabular}{|r|r|}
\hline \\
$\square$
\end{tabular}

25) Capacità di adattarsi alle attività di vita quotidiana

$\begin{array}{lllll}\square & \square & \square & \square & \square\end{array}$

$\square$

26) Capacità di cogliere nuove opportunità

$\square \quad \square \quad \square \quad \square \quad \square \quad \square$

$\square$ 
Table 1. Characteristic of the sample

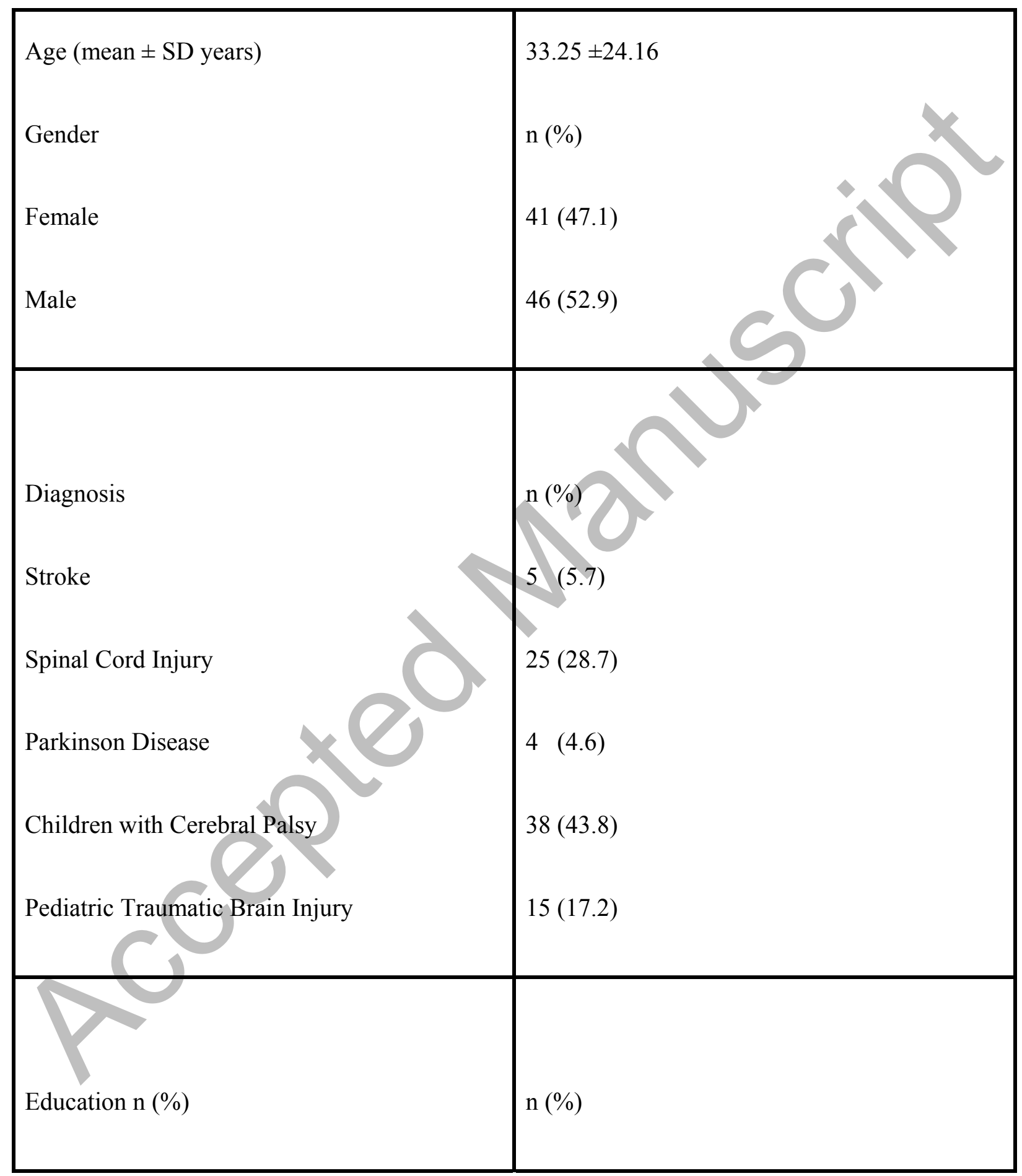




\begin{tabular}{|l|l|}
\hline Primary School & $16(18.4)$ \\
Secondary School & $37(42.5)$ \\
High School & $25(28.8)$ \\
University & $9(10.3)$ \\
\hline Form filled out by $\mathrm{n}(\%)$ & $\mathrm{n}(\%)$ \\
\hline Patient & $53(60.9)$ \\
\hline & \\
\hline
\end{tabular}


Table 2. Item-Total Statistics

\begin{tabular}{|c|c|c|c|c|}
\hline Item & $\begin{array}{l}\text { Scale Mean } \\
\text { if Item } \\
\text { Deleted }\end{array}$ & $\begin{array}{l}\text { Scale Variance } \\
\text { if Item } \\
\text { Deleted }\end{array}$ & $\begin{array}{l}\text { Corrected } \\
\text { Item-Total } \\
\text { Correlation }\end{array}$ & $\begin{array}{l}\text { Cronbach's } \\
\text { Alpha if Item } \\
\text { Deleted }\end{array}$ \\
\hline Q1 & 31,10 & 275,675 &, 567 & \\
\hline Q2 & 31,10 & 281,117 & ,490 & 913 \\
\hline Q3 & 31,09 & 279,503 &, 534 & ,912 \\
\hline Q4 & 31,06 & 279,125 & 679 & 910 \\
\hline Q5 & 32 & 303,729 &, 015 & ,920 \\
\hline Q6 & 31,23 & 281,714 & ,642 & ,910 \\
\hline Q7 & 31,59 & 279,385 &, 570 & ,911 \\
\hline Q8 & 31,30 & 271,514 & ,708 & 909 \\
\hline
\end{tabular}




\begin{tabular}{|c|c|c|c|c|}
\hline Q9 & 31,11 & 279,405 & ,605 & ,911 \\
\hline Q10 & 32,66 & 307,856 &,- 090 & ,923 \\
\hline Q11 & 30,89 & 286,987 & ,443 & ,914 \\
\hline Q12 & 31,38 & 280,331 &, 544 & \\
\hline Q13 & 31,18 & 278,780 & ,693 & ,909 \\
\hline Q14 & 31,23 & 281,598 & .638 & 910 \\
\hline Q15 & 31,43 & &, 503 & ,913 \\
\hline Q16 & 31,1 & 282,276 & ,684 & 910 \\
\hline Q17 & & 287,509 &, 511 & ,913 \\
\hline & 30,95 & 276,882 & ,746 & ,909 \\
\hline Q19 & 31,28 & 278,388 & ,665 & 910 \\
\hline
\end{tabular}




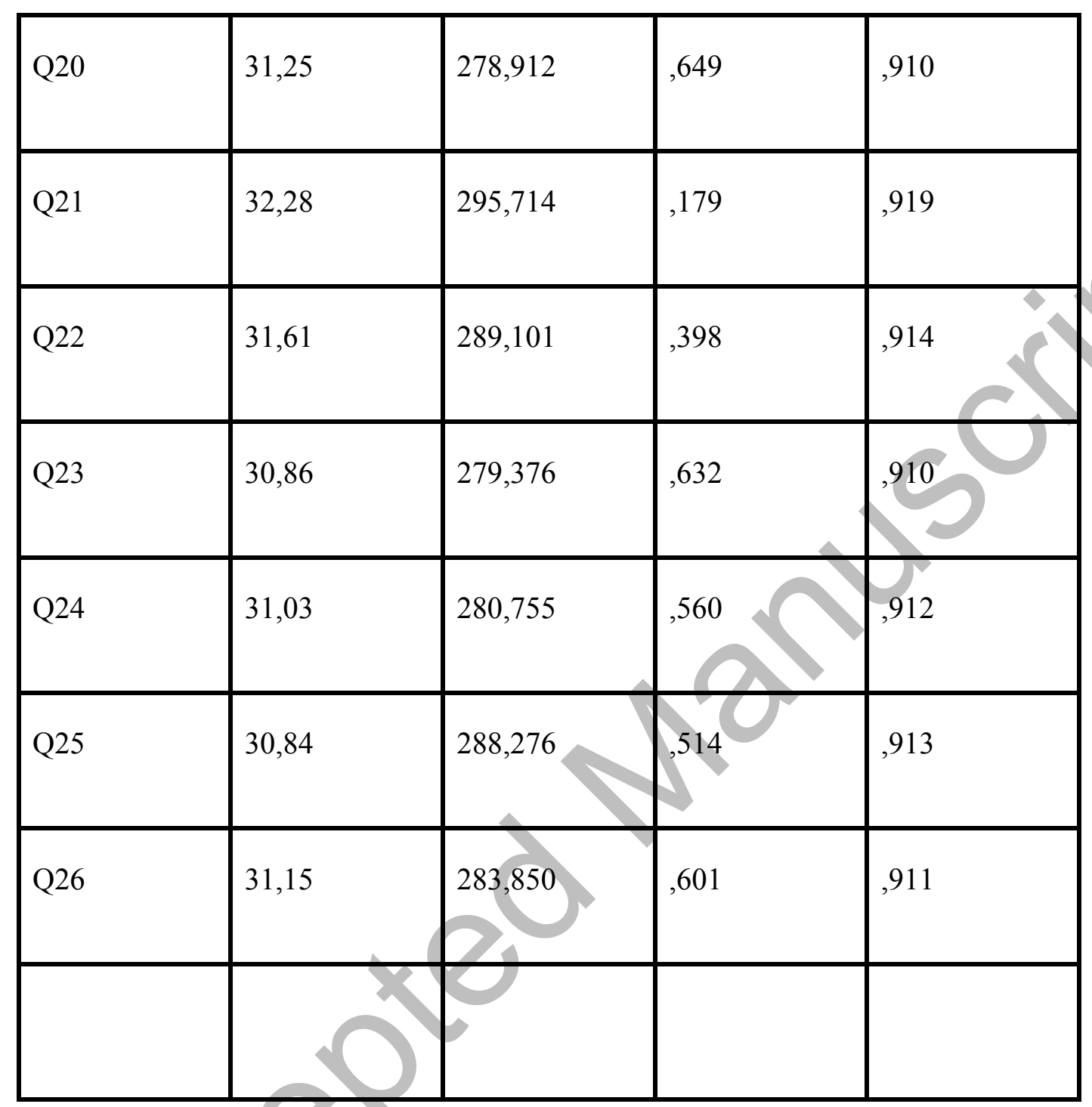


Table.3 Test-retest reliability

\begin{tabular}{|l|l|l|l|}
\hline Subscales & Intraclass & Lower & Upper \\
\hline Competence & 0.96 & Bound & Bound \\
\hline Adaptability & 0.90 & 0.90 & 0.98 \\
\hline Self-esteem & & 0.78 & 0.95 \\
\hline Total & 0.93 & 0.85 & 0.97 \\
\hline
\end{tabular}


Table 4 Pearson Correlation Coefficient

\begin{tabular}{|l|l|l|}
\hline & Competence & Adaptability \\
\hline WheelCom Physical &, $343^{*}$ &, $463^{* *}$ \\
\hline WheelCom Environment & &, $406^{*}$ \\
\hline WheelCom Total &, 280 & $*$ Correlation is significant at the 0.05 \\
\hline level (2-tailed). & & \\
\hline
\end{tabular}

